\title{
O FAZER POÉTICO INFANTIL, ENSINO FUNDAMENTAL I: A TEORIA PELOS
} RESULTADOS.

\author{
Marilani Soares Vanalli ${ }^{1}$, Débora Jacqueline de Jesus ${ }^{2}$ \\ Universidade Estadual Paulista - UNESP, ${ }^{1}$ Doutorado em Literaturas de Língua Portuguesa, Assis, SP. ${ }^{2}$, Curso de Arte- \\ Educação, Presidente Prudente, SP. marilanivanalli@hotmail.com
}

\section{RESUMO}

Desde o primeiro contato com poesias, até alcançar o fazer poético, o intuito foi desnudar ao leitor um universo diferenciado, lúdico e que confere cintilância em cada construção lírica do poeta-mirim. 0 objetivo deste estudo foi mostrar resultados da escrita infantil e analisar tais construções poéticas sob a perspectiva do olhar da criança. A metodologia constou de prática da sala de aula à análise teórica dos textos. Como fundamentação teórica autores que compreendem poesia como algo que transcende a linguagem em seus vários aspectos. Os resultados foram que ao fazer a relação da teoria com as construções das crianças constata-se a liberdade de expressão que esse gênero oferece. Partindo das poesias elaboradas pelos alunos conclui-se que o fazer poético infantil depende da liberdade criadora e subjetiva que a poesia oferece bem como a musicalidade provocada pelo modo como é estruturada, revestindo-se de um caminho inovador do fazer poético infantil.

Palavras-chave: Poesia, leitura, fazer poético, sala de aula, Ensino Fundamental I.

\section{THE CHILD'S POETIC PROCESS, ELEMENTARY SCHOOL: THEORY AS A RESULT OF THE PRACTICE.}

\begin{abstract}
Since the first contact with these texts until the achievement of their own poetic process, the intent is to display to the reader a different poetic universe; playful nature conferring brilliance in each lyrical creation of the young poet. The goal is to show results of child writing and analyzing these poetic constructions under the child's perspective. The methodology was based on classroom practice and theoretical analysis of the texts. As theoretical basis authors who understand poetry as something that transcends language in its several aspects. The results were that in establishing the relationship between theory and construction of the children freedom of expression, offered by this genre, is found. Based on the poetry produced by students it is concluded that child's poetic process depends on the creative and subjective freedom that poetry offers and musicality caused by the way it is structured becoming an innovative approach of child's poetic process.
\end{abstract}

Keywords: Poetry, reading, poetic process, classroom, Elementary school 


\section{INTRODUÇÃO}

Trabalhar com poesias pode ser muito relevante para o desenvolvimento cognitivo, intelectual e emocional do aluno, quando se pensa no ser holístico e na desenvoltura das múltiplas competências e habilidades. A educação poética busca formar uma comunidade de leitores que se constrói na sala de aula, no intuito de conquistar o hábito de leitura dos educandos. A ideia é oferecer aos alunos, por meio da poesia, individual e coletivamente, uma maneira própria de ver/viver o mundo.

O trabalho com poesias facilita ao aluno o contato com os livros literários e, se aliados às estratégias de leitura e compreensão textual, possibilitam o exercício da reflexão; valorização do lirismo e apreciação do trabalho de escritores renomados ou não.

O objetivo deste trabalho é revelar que oportunizando o espaço para a leitura de poesia em sala de aula, descortina-se à fantasia e se desperta à sensibilidade lírica ou engajada do leitor, estabelecendo intertextualidades e a força polissêmica que as palavras contêm.

Desta forma, pretende-se revelar o resultado que se pode alcançar com crianças do Ensino Fundamental, ciclo um, de um trabalho com poesias em sala de aula.

\section{METODOLOGIA}

Vários são os gêneros trabalhados em sala de aula. No entanto, há mais ênfase no Ensino Fundamental I para a literatura infantil narrativa: os contos, as fábulas, as adivinhações, parlendas e músicas folclóricas, onde a prioridade são os textos em prosa. A poesia fica nas periferias do saber, esquecida tanto nas prateleiras de sala de aula como nas salas de leitura escolares. Alguns aspectos são considerados inicialmente relevantes:

- É um gênero atrativo tanto aos olhos quanto aos ouvidos do leitor/ouvinte. Desta forma, de início prende-se a atenção da criança pelo jogo sonoro e de imagem que a poesia apresenta.

- $\quad$ O engendrar das palavras é outro aspecto favorável ao trabalho com poesia em sala de aula, a conexão que elas estabelecem com os versos e estes com o todo acontecem de forma concatenada. Isso facilita tanto a leitura dinâmica quanto o entendimento mais aberto e subjetivo que a poesia oferece, já que "o texto poético não deve servir de pretextos moralizantes" (Pinheiro, 2007, p. 21).

- A relação poeta-criança acontece de forma lúdica, sem intenções ou pretensões, sem pressupostos. A criança compreende que poesia é o brincar com as palavras, e que o que está 
em jogo são seus anseios, desejos, criação, é um sistema ou plano que parece ser uma fantasia, um devaneio, uma ilusão, um sonho. E são esses aspectos que satisfazem o leitor mirim.

- Com a frequência das leituras de poemas, as crianças, de modo gradativo, apreendem qual a função social da poesia, pois suas emoções e sensibilidades são aguçadas e a cada nova leitura acontece sempre comunicação de alguma nova experiência.

No entanto, o trabalho com textos poéticos na sala de aula é uma experiência íntima entre criança poeta-mirim e palavras. Trabalha-se com a exposição de sentimentos, tão individual e particular que se observa pelos gestos; pelo brilho no olhar; pela fala; por expressões artísticas; pela surpresa que cada criança guarda para expandir-se e explorar neste momento único. Com efeito, entram em jogo, vários outros aspectos interligados ao trabalho com poesias, visto que consequentemente ocorre o aprimoramento, o enriquecimento da linguagem bem como da apropriação de outros textos poéticos, do uso de metáforas para representar e apresentar aquilo que as palavras não podem dizer. Paz $(1982$, p. 57) ilustra bem isso quando diz "Poema: ouvido que escuta uma boca que diz o que não disse a exclamação".

\section{RESULTADOS}

Para ilustrar a poesia sob a perspectiva do olhar da criança fala-se, então, sobre sentimento poético. POEMA "Se eu pudesse voar e cantar"

Se eu pudesse voar

Iria até o além

Procurando onde cantar

Cantar pra você também

Cantando uma linda melodia

Com amor e prazer

Quanto mais voava mais crescia

Com essa alegria que contagia

Como não posso voar

Fico imaginando...

À espera de um dia poder flutuar

Flutuar e pensar...

(Gabriel e Guilherme - 9 anos) 
O poema está separado em estrofes e há presença de rimas. A escolha pela criança foi de um poema com rima externa, como se pode confirmar em: (voar-cantar / além-também / melodia-crescia-contagia / voar-flutuar-pensar).

Quanto à disposição das rimas na 1. a estrofe aparecem alternadas ( $A B A B)$, mas na 2. a e 3. estrofes são as misturadas (ABAA). A criança percebe a musicalidade dos poemas pelas rimas, as quais ela considera não como estrutura rítmica, mas uma brincadeira feita por quem escreve poesia.

Em nível morfológico, a escolha dos vocábulos pelo aluno seja simples, e composta por verbos, à relação lógica das palavras nas frases, nos versos (sintaxe), expõe o modo como apresenta seu desejo surreal diante de uma vontade que ele sabe impossível. Porém, entende que voar expressa o ir além do aqui e agora, e que cantar é uma ação que traz algum tipo de sentimento, tanto a si mesmo quanto às pessoas: alegria, amor, emoções, desapego daquele instante em que se canta ou ouve uma canção.

Outro aspecto utilizado pelo aluno é o uso das reticências, elemento de pontuação que evoca uma continuação do pensamento, indo muito além do desejo de voar e cantar simultaneamente. Bosi (1977, p. 60) atenta para esse detalhe: "e até do silêncio, que parece puro vazio, ausência de som, o espírito arranca um mar de significados". As reticências estão dispostas depois das palavras 'imaginando' e 'pensar', deixando para o leitor refletir sobre a subjetiva continuidade de tais palavras.

O entendimento desse aluno é que na poesia as palavras são livres, soltas, podendo representar o que o pensamento permitir, ultrapassar o entendimento lógico, assim o seu desejo interior é expresso na superfície do texto poético.

Bosi (1977, p. 27) referenda que "Frases não são linhas. São complexos de signos verbais que se vão expandindo e desdobrando, opondo e relacionando, cada vez mais lastreados de somsignificante." Como menciona Bosi, cada verso se completa tanto em conjunto no poema como em si mesmo, compondo assim, o efeito sonoro, o ritmo por meio da rima, a imagem e o significado que cada verso emite ao leitor, porque "poeta e leitor são dois momentos de uma mesma realidade" (Paz, 1982, p. 47).

O universo de sensações que envolvem o tema do poema da criança conduz o leitor a um sentimento denso de liberdade e leveza, revelado pela imagem que o poema apresenta.

O aspecto relacionado à sonoridade do texto do aluno, embora haja oscilação entre sibilante e vibrante, apresenta-se mais voltado a este que aquele, utilizando palavras mais intensas, fortes, vibratórias que sussurrantes. A escolha dos vocábulos remete tanto a sons orais 
quanto nasais, concebendo ao poema uma ludicidade sonora, um vaivém no jogo de palavras que traduz o repertório da criança e o sentido subjetivo que ela dá a cada verso.

A relação das palavras com o texto, expressa uma característica em que Bosi (1977, p. 35) denota poeticamente acerca da organização da superfície "que o som e todos os seus ecos venham adensar a face concreta do poema". Desse modo percebe-se a singularidade rítmica de cada verso estabelecendo a coerência poética, que complementa a estratégia subjetiva do dizer e do fazer poético da criança.

A partir do momento em que são apresentados os textos poéticos, o interesse por este gênero tende gerar inquietação e prazer dependendo do modo como sejam trabalhados. exercício de ouvir a leitura de poemas de modo consciente, expressivo e com dose de emoção transmite a sensação que a poesia oferece: a essência da sensibilidade poética. Declamar um poema assemelha-se ouvir uma música; deve proporcionar o mesmo prazer. O aluno é exposto a um repertório de textos poéticos para que suas produções possam ter como referência a estrutura desses textos bem como a ideia de como é o "brincar com palavras" de que tanto fala José Paulo Paes.

A intertextualidade manifestada na produção poética do aluno representa as leituras apresentadas em sala de aula. Neste contexto, os poemas de José Paulo Paes, Cecília Meireles e Roseana Murray assumem papel preponderante na inspiração da escrita poética. $O$ aluno tende a lidar de um modo particular com as imagens que vão se formando ao encontrar-se com a poesia e espontaneamente constrói seu próprio texto.

A leitura de poemas variados é um dos recursos que enriquecem o conhecimento do aluno, mesmo que ele escreva de maneira inconsciente em relação aos poemas já trabalhados. Com relação à estrutura poética sente-se fluidez e uma espontaneidade inconsciente, as palavras ficam compreendidas no seu repertório de construção da linguagem e, para reforçar, Paz (1982, p. 45) denota que "A linguagem é poesia e cada palavra esconde certa carga metafórica disposta a explodir tão logo se toca na mola secreta; a força criadora da palavra reside, porém, no homem que a pronuncia".

\section{DISCUSSÃO}

Trabalhar com a criança do Ensino Fundamental ciclo I traz sabor diferente: ensinar o gosto pela poesia, antes até da criança ser exposta à escrita mais normativa. A poesia é inerente ao humano, seja em uma música de ninar, numa cantiga de roda, como adivinhação, parlenda, numa paisagem, no som da natureza, numa imagem ou e num gesto de amor. 
A descoberta de que as aulas de poesia é um universo sem fim, onde flui a vontade, verdade, sentimentos se afloram e a subjetividade torna-se aliada aos textos poéticos. É o lugar onde as reticências (...) têm sentido especial, quando se tornam mais que infinitas.

O fazer poético, delineia todo o jogo de significados diferentes pensados e repensados pelo poeta e, da mesma forma, a criança é envolta nesse jogo rítmico e simbólico que as palavras oferecem. O universo poético pelo olhar das crianças é ilimitado: não existe certo ou errado, feio ou bonito. O que existe é a liberdade que todo adulto gostaria e deveria ter.

Pensar em leitura de poesia é aventurar-se numa instância artística desprovida da previsível linearidade, e pensando com Paes (1993, p. 24) "e sim num ir e vir entre o que está adiante e o que ficou atrás", sem transmitir normas morais ou conhecimento sistematizado, nem interpretá-lo literalmente.

Ler um poema em sala de aula conduz a criança à singularidade da linguagem. Trabalha-se com o ouvir, sentir e expressar-se, estabelecendo uma relação com o texto lido por meio de comentários, comparações e intertextualidades a outros textos e imagens, enriquecimento do repertório de vocabulário, o compartilhar de ideias, as expectativas. Ou seja, os resultados daquilo que idealizou e construiu e, preparar para seguir em frente à busca por textos mais complexos.

A ambientação literária reserva momentos para a literatura infantil em que o espaço privilegiado não seja somente para os livros de histórias, como também para a poesia. Os alunos aprendem a apreciar a linguagem poética pelo valor que as palavras contêm.

A criança é toda emoção e razão, afetividade e cognição, intuição e racionalidade, a paradoxalidade que revela o ser humano, de uma subjetividade que não se deve ignorar. Sabe-se que as produções, sejam elas em prosa ou não, terão significados singulares, já que as palavras serão revestidas semanticamente da plurissignificação.

No repertório em constante construção, surgirão palavras que deixarão os textos mais ricos e agradáveis de serem lidos, apreciados, ou seja, será muito mais construtiva a aventura de mergulhar no texto.

Considera-se importante declamar poesias, enfatizando o jogo sonoro que possuem - o ritmo, as repetições, as rimas - o encantamento do texto poético, o caráter lúdico que traz a poesia infantil. A criança aprecia a poesia antes mesmo da apreensão do sentido e, aos poucos, vai conquistando sua própria expressão, de alguma forma identificando-se com ela, estabelecendo relação com o mundo.

O poeta transforma em imagem suas ideias e sentimentos, revelando-se o avesso das palavras, o outro sentido do que se quer expressar. Extravasam-se estilos e estrutura poética. Com 
a criança não é diferente. No entanto, não há pretensão de trabalhar com regras ou estilos estruturais em sala de aula, porém é imprescindível destacar que o professor deve conhecer profundamente tais teorias para em aula, usá-las e ao apoiar-se nelas, demonstrar consciência e conhecimentos necessários para auxiliar o momento do fazer poético infantil.

Explorar o efeito lúdico-imaginativo do texto poético não significa que não apareçam tais recursos nas produções dos alunos, porém o fazem de modo espontâneo e divertido. Despertamse a cada leitura o jogo de palavras aprendidas e os momentos da leitura deleite, sem esperar nada como recompensa, mas leitores que saibam apreciar o sabor, o cheiro, o valor que cada palavra tem: desnudar a essência do texto literário lido por sua própria escolha.

\section{CONCLUSÃO}

O referido estudo mostra a intimidade/liberdade com as palavras e o envolvimento com o texto poético, seja ele estruturado com rimas ou não. Naturalmente as figuras de linguagem surgem espontaneamente devido à observação de cada uma das palavras a cada leitura ou exposição dos poemas. Neste contexto, os textos poéticos vão se construindo paralelamente, tomando consistência temática, de linguagem, sonoridade e quanto à forma.

A significação das palavras vai se fortalecendo e criando uma relação escritor-leitor, estabelecendo uma ligação intrínseca entre o que se quer escrever, para que escrever e para quem escrever. A criança, por meio do equilíbrio do seu pensamento e com um trabalho bem direcionado, conforme vai amadurecendo, percebe que ao escrever não o faz tão somente para ela, mas para alguém que está alheio ao contexto daquele momento. 0 fato de priorizar o trabalho com poesias não significa que não se estenda a textos literários em prosa, pelo contrário, o repertório de textos precisa ser vasto para que haja ampliação do léxico; de ideias; conexões com textos de gêneros diversos; reflexões e debates acerca de preferências e gostos.

Os temas trabalhados são os mais variados, adequados à turma, já que o importante é oferecer um repertório vasto de literatura poética ou não, de modo que os alunos se sintam à vontade para escolher aquilo que melhor lhes aprouver.

Este estudo pretende revelar experiências vividas em sala de aula, refletidas, experimentadas e construídas em conjunto com as crianças que são o cerne do trabalho com poesias. Percebe-se que a partir de textos poéticos o trabalho de sala de aula torna-se mais agradável, significativo e facilitador dos demais conteúdos, uma vez que a poesia acaba por ser a "ponte" entre o que é esperado e real e o inesperado e figurado. Tais exemplos ilustram que a criança tem ideia de que a poesia é algo que vai além do que as palavras podem expressar; que é 
possível descrever algo que ao mesmo tempo em que seja abstrato no plano real, torna-se concreto no jogo lúdico e de palavras libertas dos padrões rígidos e normativos da língua. Selecionar a poesia como ponto de partida para o trabalho com textos, torna-se mais compreensível à utilização das palavras, o porquê das palavras, a colocação e sentido em vários outros gêneros e, como resultado, a produção de textos: os mais diversos, envolventes, inusitados, que a imaginação possa expressar. Vale à pena arriscar, já que só o fazer poético poderá explicar os resultados surpreendentes que ele traz.

Vamos brincar de poesia?

\section{REFERÊNCIAS}

ABRAMOVICH, Fanny. Literatura Infantil: gostosuras e bobices. - São Paulo: Scipione, 1989.

ANDRICAÍN, Sérgio; RODRIGUEZ, Antonio Orlando. Escuela y poesia:? Y qué hago com el poema? 1. Ed. Buenos Aires: Lugar Editorial, 2009.

BOSI, Alfredo. O ser e o tempo na poesia. São Paulo: Cultrix, ed. Da Universidade de Sã Paulo, 1977.

COHEN, Jean. Estrutura da linguagem poética. Trad. Álvaro Lorencini e Anne Armchand. São Paulo: Cultrix, ed. Da Universidade de São Paulo, 1974.

PAES, José Paulo. É isso ali. Rio de Janeiro: Salamandra, 1993.

Poemas para Brincar. 14 ed. São Paulo: Ática, 1999.

PAZ, Octávio. O arco e a lira. Trad. de Olga Savary. Rio de Janeiro: Nova Fronteira, 1982.

PINHEIRO, Hélder. Poesia na sala de aula. Campina Grande: Bagagem, 2007. 133p. 